\title{
Overview of Microstrip Patch Antenna for GNSS communication System
}

\author{
Shweta Tamrakar \\ M.Tech Scholar \\ Department of Electronics and Communication \\ SISTec Bhopal (M.P.)
}

\author{
Prof. Rahul Shrivastava \\ Assistant Professor \\ Department of Electronics and Communication \\ SISTec Bhopal (M.P.)
}

\begin{abstract}
Microstrip patch antenna are playing very important role in all wireless global navigation satellite communication system. It uses L band, $\mathrm{X}$ band, $\mathrm{C}$ band, Ku band, Ka band for global navigation satellite system (GNSS) communication application. L band frequency range is 1$2 \mathrm{GHz}$ so it can be used in lower frequency range communication. With the increasing need for communication and the emergence of many other systems, it is important to design compact size antennas to cover a wide frequency range. The design of an efficient wideband small size antenna, for recent wireless applications, is a major challenge. Patch antennas have found extensive applications in wireless communication system. In this paper microstrip patch antenna discussed and detail studied of GNSS system application.
\end{abstract}

Keywords-Antenna, Electromagnetic propagation, Microstrip antenna, GNSS.

$* * * * *$

\section{INTRODUCTION}

Satellite-based navigation systems utilize an adaptation of triangulation to find the client, through computations including data from various satellites. Each satellite transmits coded signals at exact interims. The beneficiary believers flag data into position, speed, and time gauges. Utilizing this data, any beneficiary on or close to the world's surface can figure the correct position of the transmitting satellite and the separation (from the transmission time delay) among it and the recipient. Organizing current flag information from at least four satellites empowers the collector to decide its position. For satellites in low earth circles, impressively less order antennas are typically utilized. Signs are probably going to be gotten and transmitted over an a lot more extensive edge, and these will change as the satellites move. In like manner these satellites only occasionally utilize explanatory reflector antennas.

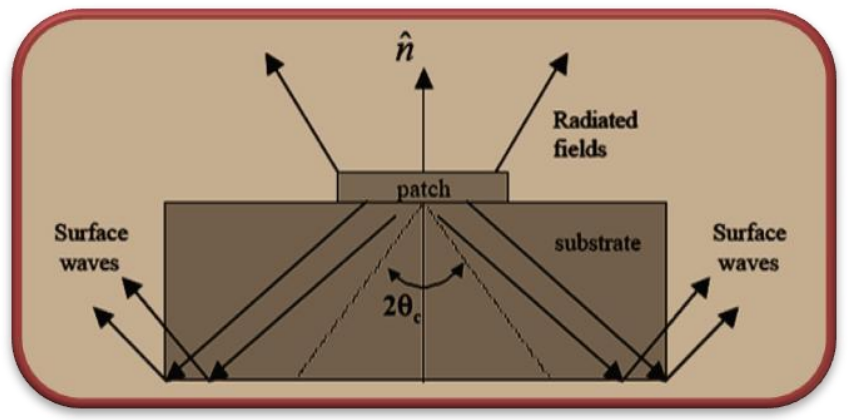

Figure 1: Field lines radiating from a patch antenna; illustrates the formation of surface waves

Ground antennas utilized for getting satellite flags and transmitting to the satellites differ extensively as indicated by their application. Again illustrative reflectors are the most broadly utilized, yet Yagi antennas might be utilized on events. The span of the antennas may change significantly. The allegorical reflectors utilized for satellite TV gathering are little. Anyway those utilized for expert applications are a lot bigger and may go up to a few many meters in size.

L-Band is additionally utilized for low earth circle satellites, military satellites, and earthbound remote associations like GSM cell phones

\section{LITERATURE OVERVIEW}

C. Sun, Z. Wu and B. Bai [1] the bandwidth of antenna will diminish with the decline of antenna size and this component constrains the structure of smaller Global Navigation Satellite System (GNSS) patch antenna (1.1-1.6 GHz). In this correspondence, a novel wideband strategy dependent on the mode examination on the shorting load patch antenna is proposed. By changing the position and the extent of the shorting load structure, the overwhelming thunderous method of patch antenna(TM 10 ) is isolated into two auxiliary modes and these two modes are consolidated together to frame a wide working band. It is demonstrated this new strategy has preferred bandwidth improvement impact over the customary strategies. By using this proposed strategy, a minimized circularly polarization wideband patch antenna is intended for GNSS application, which has a little electrical size of just $0.2 \lambda$ $0 \times 0.2 \lambda 0 \times 0.05 \lambda 0 .(\lambda 0$ is the wavelength of low band in free space.) The reproduced and estimated results demonstrate that the proposed antenna has great and stable execution over the entire working band, which implies that it is a significant perfect conservative antenna utilized for GNSS satellite navigation applications.

A. S. W. Ghattas and E. E. M. Khaled [2] A vicinity feed ultrawide band (UWB) patch antennas with a smaller size (millimeters estimate) for $\mathrm{Ku} / \mathrm{K}$ band applications is introduced. Deserted ground structure (DGS) strategy is utilized to expand the bandwidth of the antenna. The proposed 
antenna presents UWB execution in the frequency scope of 16 $\mathrm{GHz}$ to $29 \mathrm{GHz}$ with a minimal size of $7 \times 10 \mathrm{~mm} 2$, which is reasonable for some applications. The examination and structure of the proposed antenna are researched with the industrially accessible programming CST microwave studio (MWS) test system. The proposed structure is created and tried. The deliberate information of the created antenna exhibits a decent concurrence with the mimicked outcomes. The proposed antenna indicates omnidirectional radiation design with a normal gain of $3.5 \mathrm{dBi}$ and great radiation productivity over the working band.

K. K. In this way, K. M. Luk and C. H. Chan [3] Patch antennas are generally connected in current remote correspondence systems. In any case, customary patch antennas have the drawback of limited bandwidth and are not appropriate for $\mathrm{Ku}$-band satellite communicate gathering. Numerous analysts have proposed different systems to upgrade the bandwidth of test encouraged patch antennas, e.g., utilizing thick substrate, including parasitic patches either in a similar layer (coplanar) or in another layer (stacked), and utilizing capacitor-stacked patches. With the main procedure, the substrate thickness increments and initiates the excitation of surface waves. Aside from lessening the radiation productivity, these surface waves diffract at the substrate edges and fall apart the radiation designs. The nearness of coplanar and stacked geometry has the inconvenience of expanding the territory and thickness of the antenna, individually. Extra capacitors cause antenna gain decrease due to the ohmic loss of the stacking chip resistor.

H. Al-Saedi, W. M. Abdel-Wahab [4] This letter introduces the structure of a wideband circularly spellbound antenna, working at Ka band. The proposed antenna contains a round microstrip patch antenna that is coupled to a microstrip feedline through a changed L-formed opening space. The antenna transmits a wideband right-hand circularly energized wave with high polarization immaculateness and a wide pivotal ratio (AR) rakish beamwidth. A $4 \times 4$ antenna subarray has been structured, created, and estimated to approve the proposed idea. The cluster shows a reflection coefficient S11 <; - $10 \mathrm{~dB}$ over the frequency band 27-31 GHz. In addition, the $4 \times 4$ antenna subarray yields an abnormal state of polarization immaculateness, and also a level estimated $\mathrm{AR} \leq 1.15 \mathrm{~dB}$ over the frequency go $27.55-30.45 \mathrm{GHz}$ ( $10 \%$ bandwidth).

L. Wang, Z. Weng, Y. Jiao, W. Zhang [5] A position of safety broadband circularly spellbound (CP) microstrip antenna with a wide beamwidth is proposed for a global navigation satellite system. Four hook molded parasitic branches are put on the sides of the ground to augment the impedance bandwidth (IBW) and half-control beamwidth (HPBW) all the while. A few openings are scratched on the radiation patch to acquire impedance coordinating. The proposed antenna is manufactured and estimated. The trial results demonstrate that the IBW for VSWR $\leq 2$ is $72.5 \%$ from 1.02 to $2.18 \mathrm{GHz}$, and the $3 \mathrm{~dB}$ pivotal ratio bandwidth is $54 \%$ from 1.15 to $2 \mathrm{GHz}$. The HPBW is past $100^{\circ}$ by and large CP bandwidth. Its measurements are $70 \mathrm{~mm} \times 70 \mathrm{~mm} \times 12 \mathrm{~mm},(0.35 \times 0.35 \times$ 0.06) $\lambda 03$, where $\lambda 0$ is the wavelength of the middle frequency.

\section{A. Application of different band}

L band - Global Situating System (GPS) transporters and furthermore satellite cell phones, for example, Iridium; Inmarsat giving correspondences adrift, land and air; WorldSpace satellite radio.

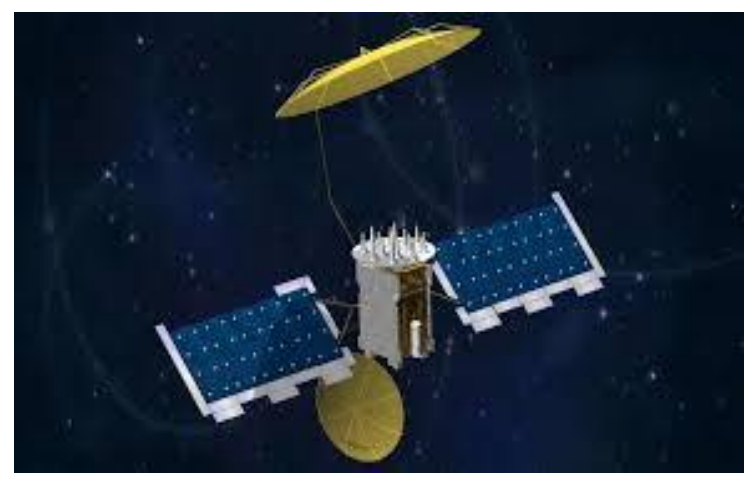

Figure 2: Satellite Antenna

S-band (2- $4 \mathrm{GHz}$ )- Climate radar, surface ship radar, and a few correspondences satellites, particularly those of NASA for correspondence with ISS and Space Transport. In May 2009, Inmarsat and Solaris versatile (a joint endeavor among Eutelsat and Astra) were granted each a $2 \times 15 \mathrm{MHz}$ bit of the S-band by the European Commission.

C band-Principally utilized for satellite interchanges, for fulltime satellite Telecom companies or crude satellite feeds. Regularly utilized in territories that are liable to tropical precipitation, since it is less helpless to rainfade than $\mathrm{Ku}$ band (the first Telstar satellite had a transponder working in this band, used to hand-off the principal live transoceanic television motion in 1962).

$\mathrm{X}$ band-Principally utilized by the military. Utilized in radar applications including ceaseless wave, beat, singlepolarization, double polarization, manufactured opening radar and staged exhibits. X-band radar frequency sub-bands are utilized in common, military and government establishments for climate checking, airport regulation, sea vessel traffic control, guard following and vehicle speed recognition for law requirement.

$\mathrm{Ku}$ band-Utilized for satellite interchanges. In Europe, $\mathrm{Ku}$ band downlink is utilized from $10.7 \mathrm{GHz}$ to $12.75 \mathrm{GHz}$ for 
direct communicated satellite administrations, for example, Astra.

Ka bnad-Correspondences satellites, uplink in either the 27.5 $\mathrm{GHz}$ and $31 \mathrm{GHz}$ bands, and high-goals, short proximity focusing on radars on military flying machine.

\section{ANTENNA FOR SATELLITE SYSTEM}

It All GPS sign are in the L-band of the frequency spectrum (1-2 GHz). Since L-band waves infiltrate mists, haze, downpour, tempests, and vegetation, GPS units can get exact information in every climate condition, day or night. There are conditions in which GPS units may not get flag precisely, for example, inside solid structures or under substantial woods shades.

The decision of the GPS carrier frequency (to transport information signals) was submitted to the accompanying necessities:

- Frequencies ought to be underneath $2 \mathrm{GHz}$, as frequencies over $2 \mathrm{GHz}$ would require pillar recieving wires for the sign gathering.

- Ionospheric delays are colossal for frequency seethes underneath $1,000 \mathrm{MHz}$ or more $10 \mathrm{GHz}$.

- The PRN codes require a high bandwidth for code tweak on the carrier frequency. In this way, a scope of high frequencies with the likelihood of a high bandwidth must be picked.

- The picked frequency ought to be in a range where the sign spread isn't affected by climate marvels like downpour, snow, or mists.

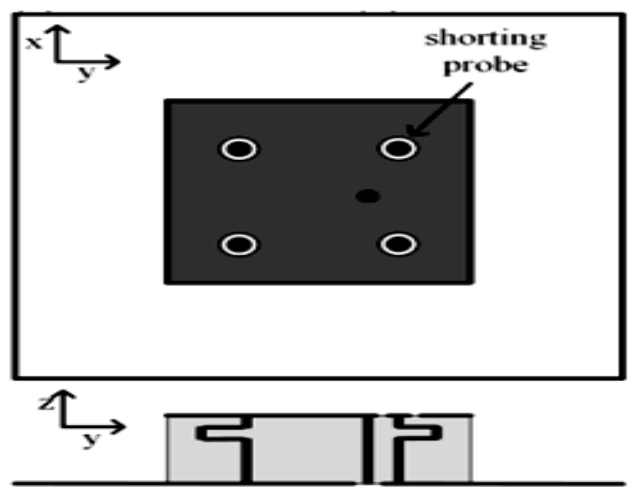

Figure 3: Previous design[1]

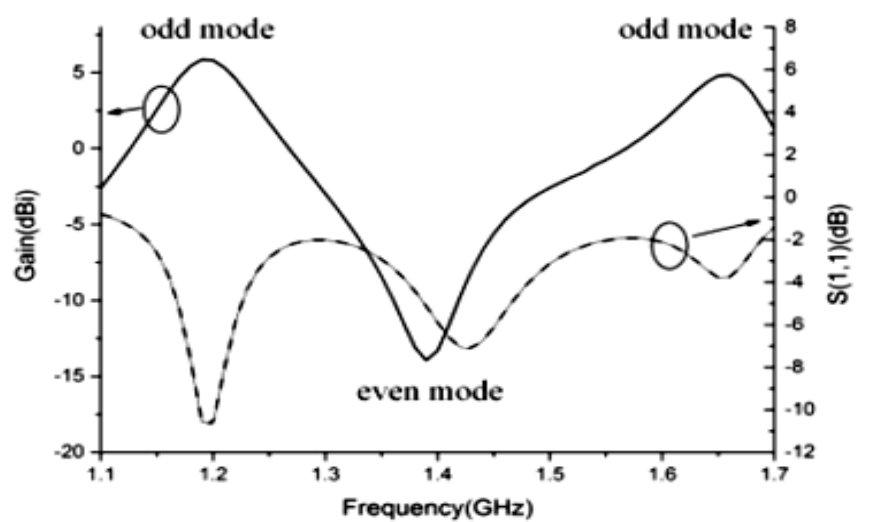

Figure 4: Return loss and bandwidth[1]

In light of these contemplations, the decision of L-band frequencies demonstrated to be favorable. Every gap satellite transmits three carrier flag in the microwave scope of the electromagnetic spectrum, assigned as L1, L2, and L5 (frequencies situated in the L-band somewhere in the range of 1,000 and 2,000 $\mathrm{MHz}$ of the spectrum).

The $\mathrm{L} 1$ frequency is $1,575.42 \mathrm{MHz}$ (wavelength $19.05 \mathrm{~cm}$ ), the L2 frequency is $1,227.60 \mathrm{MHz}$ (wavelength $24.45 \mathrm{~cm}$ ), and the L5 frequency is $1,176.45 \mathrm{MHz}$ (wavelength $25.48 \mathrm{~cm}$ ).

\section{CONCLUSION}

Every antenna has its own legitimacy and negative marks one can choose the reasonable approach in light of the application and prerequisite. From audit of various radio wire outlines, $\mathrm{L}$ band microstrip patch antenna studied and it is finding that it will be better for GNSS application if antenna bandwidth improved.

\section{REFERENCES}

[1]. Chao Sun, Zhao Wu, and Bowen Bai" A Novel Compact Wideband Patch Antenna for GNSS Application" IEEE journal 2017

[2]. M. Chen and C. C. Chen, "A Compact Dual-Band GPS Antenna Design," IEEE Antennas \& Wireless Propagation Letters, vol. 12, pp. 245-248, 2013.

[3]. S. Gupta and G. Mumcu, "Dual-Band Miniature Coupled Double Loop GPS Antenna Loaded With Lumped Capacitors and Inductive Pins," IEEE Transactions on Antennas \& Propagation, vol. 61, pp. 2904-2910, 2013.

[4]. J. J. H. Wang, "Antennas for Global Navigation Satellite System (GNSS)," Proceedings of the IEEE, vol. 100, pp. 23492355, 2012.

[5]. J. A. Kasemodel, C. C. Chen, I. J. Gupta, and J. L. Volakis, "Miniature Continuous Coverage Antenna Array for GNSS Receivers," IEEE Antennas \& Wireless Propagation Letters, vol. 7, pp. 592-595, 2008.

[6]. M. Li and K. M. Luk, "A Differential-Fed UWB Antenna Element With Unidirectional Radiation," IEEE Transactions on Antennas \& Propagation, vol. 64, pp. 3651-3656, 2016. 
[7]. J. Y. Deng, L. X. Guo, Y. Z. Yin, J. Qiu, and Z. S. Wu, "Broadband Patch Antennas Fed by Novel Tuned Loop," IEEE Transactions on Antennas \& Propagation, vol. 61, pp. 22902293, 2013.

[8]. M. He, X. Ye, P. Zhou, G. Zhao, C. Zhang, and H. Sun, "A Small-Size Dual-Feed Broadband Circularly Polarized U-Slot Patch Antenna," IEEE Antennas \& Wireless Propagation Letters, vol. 14, pp. 898-901, 2015.

[9]. M. Arrawatia, M. S. Baghini, and G. Kumar, "Differential Microstrip Antenna for RF Energy Harvesting," IEEE Transactions on Antennas \& Propagation, vol. 63, pp. 15811588, 2015.

[10].N. W. Liu, L. Zhu, W. W. Choi, and J. D. Zhang, "A Novel Differential-Fed Patch Antenna on Stepped-Impedance Resonator With Enhanced Bandwidth Under Dual-Resonance," IEEE Transactions on Antennas \& Propagation, vol. 64, pp. 4618-4625, 2016.

[11].M. Naser-Moghadasi, A. Dadgarpour, F. Jolani, and B. S. Virdee, "Ultra wideband patch antenna with a novel foldedpatch technique," Iet Microwaves Antennas \& Propagation, vol. 3, pp. 164-170, 2009.

[12].C. Sun, H. Zheng, L. Zhang, and Y. Liu, "Analysis and Design of a Novel Coupled Shorting Strip for Compact Patch Antenna With Bandwidth Enhancement," IEEE Antennas \& Wireless Propagation Letters, vol. 13, pp. 1477-1481, 2014. 